\title{
The Issue of Global Warming Due to the Modern Misuse of Techno-Scientific Applications
}

\author{
Gabrielle Decamous
}

Additional information is available at the end of the chapter

http://dx.doi.org/10.5772/51548

\section{Introduction}

Climate change has become undeniably one of the most important challenges for our generation and the ones that follow. This challenge is such that it affects the whole of our space-time spectrum: an urgent reassessment of our present-day technology is indisputably needed, while at the same time, this challenge also requires the most accurate knowledge of the shifts in temperature in the hope for a possible and still hypothetical sustainable future. Not only this, but it will also concern - and already does - the totality of the planet and of its living creatures. The problem that climate change represents is therefore very wide and has an effect on a very broad range of human activities. However, in spite of the importance of the historical and global parameters, it appears as if the cause of the rise in temperature of our planet is first and foremost technological (because of man-made carbon emissions) and that a technological solution would consequently be needed.

After all, within the history of technology and science, every once in a while, a notable breakthrough allows for the betterment of the human condition. Agriculture, electricity, steam engines, atomic science, biotechnology, etc., mark our timeline. These breakthroughs have enriched the life of many, for the sake of 'human' needs, complementing rather than overcoming the previous techniques and technologies. An example of this complementary use is the 'Green Revolution' in which mechanised agriculture played a major role in the 1960s to the 1990s, and that even saw countries such as Mexico overproducing and therefore exporting some new types of wheat. These past and contemporary techniques and technologies therefore play a major role in easing our lives. It would therefore be logical to await for the next techno-scientific generation to revolutionize our routines.

Indeed, the question left unanswered today is the following: what technological breakthrough will come next that will serve our energy needs? Nanotechnology and 
biotechnology holds no promise of energy quality or sustainable energy as much as hydrogen fuel is not yet ready for takeoff and probably needs more investment. Another techno-scientific revolution is therefore greatly expected. Yet, let's imagine for an instant, let's put forward the fantastic hypothesis that a solution to the production of greenhouse gases has been found, that hydrogen fuel becomes affordable and marketable, that wind and solar energy can be stored, even on the scale of our planet. The problem at the origin of global warming would probably be resolved. But would the core of the problem be really solved, the one of the misuse of technology itself?

Alongside the succession of technological innovations, we also have to acknowledge the succession of catastrophes, disasters and accidents that constitute our modern history and that are as important to underscore as the techno-scientific progresses themselves. Fukushima, Chernobyl, as the most devastating technological accidents, as much as the most inhuman misuse of science in warfare strategies, such as the gas chambers and the atomic bombings. The binary use of science and technology is evident, even today, within the continuous use of weapons around the world, the on-going oil spillages, the endless industrial pollution of all types and the uncertainties concerning the safest way to store radioactive waste for the coming thousands of years.

The binary aspect of technology is in fact recurrent, in its misuse, as much as in human's unstable control over nature and even over the technological apparatuses themselves. Consequently, even if we find a technological solution to the present state of the Earth and to the production of greenhouse gases, will the problem of the misuse of technology as such be solved? This mishandling and dual use is persistent, as we will detail in this essay, and needs an appropriate framing. Indeed, what tells us that this misuse will cease to happen once global warming no longer constitutes a threat to living beings and that another threat will not be in sight in the remote future?

Our current situation therefore needs to be tackled ontologically - that is, to think and underscore the origin of the problem and of this misuse at large. Through this approach, and by way of consequences, this essay will stand in the domain of the humanities. The strategy is to understand global warming beyond (and complementary to) the scientific challenge that it represents in the world today. As unexpected as it may seem, the humanities have already dedicated much thinking to similar problems and these thoughts are as crucial to consider today as they were yesterday - for we need to think about global warming from all possible angles. This essay will adopt existing theoretical, philosophical and artistic frameworks to investigate global warming. These frameworks will permit tackling the current crisis from a wide variety of angles, such as the recurrence of apocalyptical scenarios, the emergence of the so-called 'climate-sceptics', the absolute urgency to revise the Western project of modernity and the difficulty in reaching a universal agreement to resolve the problem. Scientific research progressed rapidly in the past century and a similarly emphasis on the development of thinking in the humanities is now needed, since this will help in considering possible ways out from the current situation. 


\section{Of the modern technologies and the technology of destruction: apocalyptical thinking}

Even though an expertise is undeniably needed in this domain, it does not however require complex techno-scientific knowledge to understand the consequence of climate change: the misuse or excessive use of modern technology can lead to the destruction of the world - or at least to the destruction of its species and/or resources necessary for their survival, and this destruction is in sight. The problem of global warming can indeed be characterized very straightforwardly in such a form for now, by the destruction of our ecosystem. It is this simple yet frightening prediction that will constitute our starting point. This aspect is indeed very prominent, so much so that the term 'thermageddon' has even been coined, for instance by Greenpeace cofounder Robert Hunter.[1]

According to Hunter, and as he argued in Thermageddon, Countdown to 2030, the negative effect of the change in climate of our Earth will culminate in the year 2030, where the ice cap will have completely melted, with the result of unprecedented climatic disasters - the countdown is starting. Yet we must acknowledge here the recurrence of such apocalyptical endings. It is not the first time that humanity has been considered to be on the verge of total extinction: nuclear physicists warned us with their 'doomsday clock' as early as the 1940s after the bombings of Hiroshima and Nagasaki. We must therefore argue here, like the French philosopher Jacques Derrida did before us in the case of nuclear weaponry, the extent to which this all too human capacity of self-destruction is not new. Here is our first clue towards the framing of the current problem: the previous debates on weapons of mass destruction.

In No Apocalypse Not Now, Derrida argued in the 1980s that the post-war and Cold War anxiety of nuclear apocalypse and its hypothetical total annihilation was nothing new. As he stated: "One may still die after having spent one's life recognizing as lucid historian, to what extend all that was not new (...). One always die, humanity might well not escape the rule." [2] It is indeed human's finitude that is at stake in these debates over human's technological destruction of the environment, be it through nuclear warfare or emission of greenhouse gases. In the face of these repeated cataclysmic circumstances, one can even suspect the inheritance of religious believes, like German philosopher Günter Anders did. In the 1960s, Anders defined the fear for a nuclear apocalypse as a modern form of the Christian eschatology.[3] For Anders, the modern man re-created for himself the condition of the Christian apocalypse, when the believers awaited (and still are) for the last judgment, yet without the possibility of salvation that the Christian apocalypse envisioned. Global warming is consequently not the first time in which the end of our species or of our world has been discussed - and probably not the last either, given that space scientists are already planning the extinction of the sun in a few billion years from now.

This recurrence was also notably detected by Maurice Blanchot, another French philosopher, who pushed the argument even further as to state the lack of modernity of this nuclear apocalypse. In The Apocalypse is Disappointing, Blanchot asserted that the nuclear apocalypse, or rather the atomic terror, is in fact "a pretence", since, according to him, "what one is 
looking for is not a new way of thinking but a way to consolidate old predicaments. (...) it becomes clear that humanity will continue to run around old values, be it for all eternity."[4] Newness was one of modernity's leading criteria yet, as Blanchot pointed out, the modern apocalypse is merely a new way to restate ancestral fears and issues. Technological annihilation is therefore a recurrent problem, it actually is a technology in itself, a technology of destruction - the only difference being that nuclear apocalypse could have been (and can still be) triggered by the ruling class and the scientific-military cast, whereas the mass of Earth's citizens participates in the production of greenhouse gases, yet with no direct intention to kill anybody. Yet, to cut loose with this repeated anxiety of cataclysmic ending, we can also put forward the surprising argument, like Maurice Blanchot strikingly did before us with regard to the fear of nuclear annihilation, that even if this tipping point occurs, the span of its destruction will in fact be limited. According to Blanchot, even if it happened, the nuclear apocalypse would be "weak"[5], for it would damage our planet only and our personal universes, but it would never disrupt the rest of the course of the universe itself, that is, the whole universe.

Pushing this claim forward should not however become an excuse to avoid the imminence of the current crisis. To come back to our human scale, we also need to acknowledge, like Derrida did before us for nuclear warfare, that the two hypothetical and/or tangible events proceed from a process of dissociation, even if in different fashions. For Derrida, nuclear weapons intensified a dissociation of competences, when scientists and military men find themselves in the position of taking the final decision, within a situation whose uniqueness would be to have no pre-existing pattern, rendering difficult any expertise in the matter. Not only this, but in this hypothetical situation, the fate of many, of humankind and all living species, would be left in the hands of a few people, which precisely unravel here again any competency in the matter. As for climate change,the emphasis is on dissociation, yet a different one, the one dissociating the ancestral 'cause-effect' relationship itself. To give an arbitrary example, the effect of using a car in any place in the world does not directly affect the life of the driver, but the whole of the planet and, most importantly, in a differed and uncertain future. The dissociation is here dramatically obvious, even though every citizen of Earth does not equally participate in the cause of the current problem. More than a dissociation, global warming also includes a mechanism of individualism and indifference or guilt, once the awareness of the long-term effect of human pollution is acquired. Most drivers still use their car as they did ten to twenty years ago, in spite of the regular increases in expenses that this mode of locomotion implies. As Robert Hunter described, it still is a way of life, or at least for some in the West, while for others, it is merely a necessity, since the functioning of most societies is still based on fossil fuels.

Once again, however, this mechanism of dissociation, in this form, is nothing new. In the context of the use of napalm gas by the United States during the Vietnam War, the German filmmaker Harun Farocki framed this phenomenon in his fictional documentary Inextinguishable Fire (1969). The dissociation is suggested within the distance between factory workers and their final products, when the employees pictured do not know if they produce vacuum cleaners or some sort of specific weapons, whose effect they do not fully 
understand. While at the same time, the scientists are depicted as completely detached from reality, testing and discussing the effectiveness of napalm gas onto flies in a cold and clinical fashion. This dissociation, which adds to the dissociation of the 'cause-effect' relationship, was and still is the underlining theme of past and contemporary Western narratives, such as the notorious and fantastic Faust (1808) by Goethe, Frankenstein (1818)by Mary Shelley, and closer to us, the non-less fantastic opera Dr Atomic (2005) by John Adams. These narratives are of importance here as they underscore, by their popularity, the repeated concern towards science's doings.

In $\mathrm{Dr}$ Atomic, the physicist Robert Oppenheimer is depicted as taking an active role in convincing the American militaries to use the atomic bomb, because the bomb would have a unique effect that he qualifies in terms of iridizing luminescence and optimal dangerousness; while in Goethe's Faust, the erudite doctor who was in the search for the meaning of life and limitless knowledge, lets himself be taken by the irrationality of a supernatural phenomenon, to the point of opening his door to the disguised Devil, and therefore, to his perdition (Fig. 1). These narratives are indeed quite famously paradigmatic of such doubts in human betterment via modern scientific means, in today's world as much as at the time of the second Industrial Revolution - although Goethe's Faust was based on legends that were already popular in the sixteenth century, that is before the first Industrial Revolution, but the latter had a rather religious moralistic stance more than anything else.

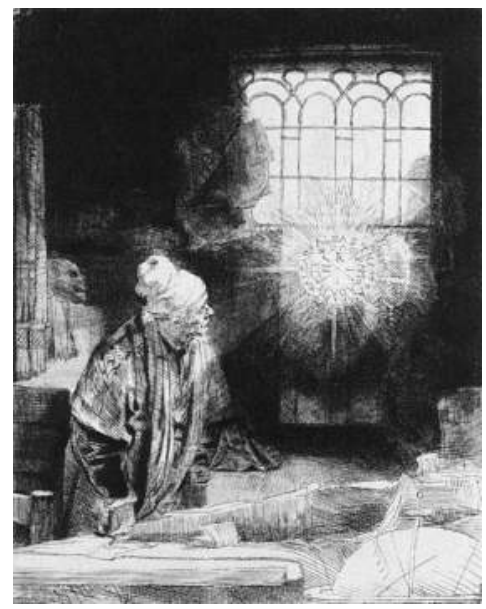

Figure 1. Rembrandt, Faust, dry-point, etching and engraving with punch, 208x160cm, Rijksmuseum Amsterdam, 1650-1652.

Whereas both narratives are nonetheless very different in context and aims, the importance of these portrayals lies not solely in their unquestionable popularity, but also in their recurrence, for they reflect the reality of an on-going anxiety in the face of the malfunctioning of our interaction with nature and our technological apparatuses. This dissociation, between the scientist's research and its actual application or even the reality of the world, is therefore not new, and is also to be added to the already existing binary 
characteristic of the use of technology that we already mentioned in the introduction. One has not to forget that contemporary to Goethe and Shelley was Jules Verne for example, who was also famously known for all the enchanting technological devices that populated his science-fiction novels. This type of rather enthusiastic stance is still detectable today. Even out of the literary circles, scientists like the post-war quantum physicist Werner Heisenberg enthusiastically stated how modern technology would overcome the entire planet, while the contemporary French philosopher Paul Virilio even envisioned a total disembodiment of the mind thanks to advanced technology, where a 'scopic' mind would be able to travel to the other end of the universe. The dual use of the technology was therefore as present in the past as it is today.

With these mechanisms of self-destruction, of dissociation (of the relation between cause and effect) and with the binary aspect of the technological apparatus so far, we consequently have to acknowledge here the ways in which the threat of total annihilation that climate change represents today is nothing new. The aim of this essay is however not to speculate and theorize on the possible destruction of the human species' biosphere nor on the endless eschatological endings. To focus solely on the technology of destruction would be to disregard the core of the problem: the economic stakes relating to techno-scientific applications. Other characteristics of global warming consequently need to be underscored here.

\section{Of believers, sceptics and entrepreneurs}

Another unavoidable characteristic of global warming that particularly needs to be addressed here is the fact that this phenomenon is contested. There is indeed an ongoing debate between those asserting the existence of climate change, and the others, the 'climatesceptics' or 'non-believers'. Here too, this binary opposition must be underscored as a recurrence, for it echoes once again the Cold War debates between those fearing and wanting to prevent the advent of a nuclear apocalypse, and the others, those believing that the human species will never been wiped off the surface of the Earth.

Not only this, but before its relation to economic interests, our current divide is nevertheless interesting in many ways, one of which being rhetorical: Derrida already pointed out how nuclear weapons generated their own rhetoric, of 'dissuasion' and 'deterrence', while climate change has clearly created a new set of vocabulary, distinguishing for example the 'climate-sceptics' from the others, that the sceptics strategically call 'the alarmists'. Even the term 'thermageddon', that we already noted, pertains to this rhetorical characteristic that goes far toward generating terms such as 'ecocide', to name the consequence of series of actual (and incontestable) devastating phenomenon, which in today's world unfortunately became a banality. The term was recently put into strategic use by campaigners in the United Kingdom in an attempt to have it recognized by the United Nations as a fifth "crime against peace."[6] Industrialists that are polluting, as much as "climate deniers" [7], would be liable in front of the International Criminal Court, for acts as much as for words. Such a term is paradigmatic of our modern times and reflects a reality difficult to 
deny - a reality that therefore goes beyond the rhetorical condition that nuclear warfare generated.

A second interesting specificity of this divide, between the climate-sceptics and the others, is that it does not engage the scientific community alone. Indeed, this particular condition becomes quickly obvious after reading a series of press articles on the topic, and goes to its paroxysm when newspapers themselves, that are supposed to be reporting current events in an objective fashion, come to accuse one another of belonging to one category or the other, therefore slipping into the binary distinction. For example, the recent article published in February 2012 by the Guardian, titled 'Wall Street Journal rapped over climate change stance', is paradigmatic of this ongoing discussion - the Guardian accusing the Wall Street Journal of repeated bias towards, or rather, of holding a 'sceptic' position on climate change, via the stance of journalists and scientists.

Further on, the Guardian's article however holds another representative characteristic, not simply of global warming alone, but of the misuse of technology at large: the economic stakes that advanced technology represents. To be more specific, the article was in the form of a letter, published by climate change experts, against the one published by the Wall Street Journal that was signed by a community of scientists expressing their scepticism. However, as the Guardian article pointed out quite clearly, almost half of the 'non-believer' scientists worked, more or less directly, for international corporations such as Exxon. Economic stakes and the search for benefits, on the side of corporations as much as of individuals, are obvious here. Here is another clue to help in analysing our current problem, and that leads to our initial assertion, that the origin to problems such as climate change is not essentially technological.

Entrepreneurs play a significant role in our situation, with the complicity or resistance of the scientists and/or government, and this state of affairs is, once again, not a novelty. One of the most striking and obvious examples, that dates from the 1970s and 1980s, is the insistence of the physiologist Hans Jürgen Eysenck giving credit to cigarettes, amidst the growing critics against the effects of nicotine at that time. His research was funded in the majority by the American tobacco industry. [8] To list such instances, of the interference of entrepreneurs and politicians in scientific research, would in fact be endless. Yet, historically, they can be traced back to the famous and popular extortion of Galileo's recantation by the Roman Inquisition - since the interests at stake are not always directly economic and can even be ideological. Another notorious historical example is Napoleon Bonaparte's war in Egypt. Napoleon employed more than a hundred fifty scientists and scholars during his imperialist war in Egypt that he initiated in the late 1790s to compete with the British Empire. Under the cover of realizing the ideals of the Enlightenment - that had the hope of archiving knowledge for a better understanding of our world and for possible betterment of our human condition - Napoleon covered his imperialist moves using propaganda, aided by scholars and interprets, going as far as to declare to the Egyptians that he encountered: "Nous sommes les vrais musulmans" (we are the true Muslims). [9] 
The practical and ideological use of scientists, which took an infamously odious turn under the Third Reich, is therefore nothing new. This use is not always unidirectional, since some scientists themselves interfere with political matters, such as Einstein, who sent numerous letters to the American president Roosevelt in order to persuade him to start a nuclear military programme, in the eventuality that the Germans invented the atomic bomb first. Since the appearance of the profession of scientist itself there have always been embedded scientists, along with scientific resistance to ideological stakes. It must be said, however, that their activities are not the only activities to be targeted by political or economic interests since, as a parenthesis, artists are inevitably caught in similar situations. [10] Some artists were also counted among the team of scholars that Napoleon brought to Egypt.

To come back to the misuse of technology, this particular phenomenon has already been analysed in the post-war and Cold War context by the German philosopher Martin Heidegger. In an attempt at shedding light to the essence of technology, Heidegger characterized it not simply as 'a means to an end' when, to use his example, a Christian ritual requires the crafting of a chalice. In its place, and in his phenomenological way, Heidegger rather defined technology as a 'revealing', thanks to which nature would appear in particular ways to us, through technological apparatuses. Yet within this revealing lies a danger, according to Heidegger, as the essence of technology is also an "Enframing,"[11] or a Gestell as he called it, when men (dasein) thought they were harnessing nature, but find themselves challenged instead of mastering it. Here is an important claim that is still relevant today. Yet, for Heidegger, there is a major difference in between modern technology and the previous form of craft/technology, and this difference is of importance for our relation to technology, or more importantly, for our relation to nature.

It would seem, according to the philosopher, that nature has been put at our disposal when, in the case of a hydroelectric power station for example, "even the Rhine appears at our command."[12] Yet Heidegger's most striking critique of modern technology is that human interaction with nature is based on prospects of productivity, turning it into a mere stock or "standing-reserve"[13] as he calls it. As he stated: "Agriculture is now the mechanized food industry. Air is now set upon to yield nitrogen, the earth to yield ore, ore to yield uranium, for example; uranium is set upon to yield atomic energy, which can be unleashed either for destructive or for peaceful purposes."[14] This is the major difference between the premodern and modern technologies, according to him: a windmill does not store energy, whereas modern technology does. We must note here that Derrida, in his analysis of nuclear warfare, also underlined the race for stockpiling, that he even characterized as being capitalist, since this accumulation constitutes for him "the very movement of capitalization."[15] If Heidegger and Derrida's statements date respectively of the 1960s and 1980s, one must admit that today's technological interaction with nature has barely changed. Nature has to be generous, productive and directed toward human needs, but is put at unreasonable use, as Heidegger already underscored. It is well this unreasonable use that is problematic more than the need for stocking - a problem yet unsolved but of crucial importance in order to face the upcoming challenges such as global warming. The financial benefits that are at stake for the big energy groups are indeed too big to be re-centred 
towards a better understanding and use of the resources of the planet. This technological 'Enframing' therefore remains even today.

Ontologically, the problem of the misuse of technology is consequently not technological, as Heidegger already clearly defined the essence of modern technology as not being technological. As we just showed, the essence of technology is a revealing. The main issue to solve is the way it is handled. This is what is challenging for humans - and the most prominent aspect of the problem to solve today. Yet as Heidegger clearly stated with regard to this enframing, within the technological revealing, as much as danger lies, also lies the possibility of a certain form of "freedom," [16] for the fact that the misuse of technology is not humans' fate. There is, and must be, a possibility of salvation, if humans realize that they are, as he phrased it, the "one[s] spoken to" [17] by nature and not the other way around.

Consequently, we could imagine a new techno-scientific device that would be efficient enough to stop the production of greenhouse gases, we could imagine finding a new source of energy, a new fuel, but would this stop ideological and economic stakes? Ethics, in science, politics, art or any social activities, consequently constitute one key to resolving the problem. Yet to go further into finding the origin of our present situation, and in order to find a solution, we have now to acknowledge that these social disciplines, science, art, politics, are in the West components of or fuel for a larger project: the project of modernity, and this project is equally important to consider as it will help further in framing the recurrent misuse of techno-scientific devices, and show that, again, the source of the problem is not solely technological.

\section{Modernity, technology and domination}

Our relation to nature is therefore to be meticulously rethought and needs to be analysed further. Such a task cannot be avoided. Another characteristic of climate change, more subtle than the ones we just considered so far, is that it indeed is modern technology, or rather, modernity at large, that is at stake, which we only hinted at with Heidegger. There is indeed a more or less direct link between climate change and the advent of modernity and its spread around the world. In We Never Have Been Modern, French philosopher of science Bruno Latour explained the specificity of this relation, simply by showing the importance he sees, specifically, in the year 1989.

Within the moment of the fall of the Berlin wall, at the very moment when the West exulted at the victory of capitalism and liberalism over communism, came the first major conferences on global warming. As he stated: "In Paris, London and Amsterdam, this same glorious year 1989 witnesses the first conferences on the global state of the planet: for some observers they symbolize the end of capitalism and its vain hopes of unlimited conquest and total dominion over nature."[18] Climate change therefore shows the limits of such a system, the modern and capitalist system.

Yet for Latour, global warming is rather a symbol, of the malfunctioning of modernity. What is of prime importance for him is that the precepts of modernity themselves need to be 
revised and this is an urgent necessity. Not simply because of the consequences of the change in temperature of the planet, but also and mainly because developing countries inherit the Western modern ideals and that these ideals are partly deficient - or rather, they need to be revised and re-adjusted. First and foremost, we must note that Latour asserted his argument in the 1990s. In today's world however, modern technology is no longer the prerogative of the West alone. India has its space and nuclear programme, China its bullet train, and South Korea its nuclear programme for example. Yet the question of inheritance is of prime importance, for the reason that some of the precepts of modernity are faulty, as Latour argued, and we consequently need to underline these deficiencies.

For Latour, one of the major problems (that Heidegger also revealed before Latour), is the modern relation to nature, which is of major significance, beyond and in addition to the global economic stakes that we already underscored. This relation to nature is detectable in the West in a twofold movement: the first movement is the way in which modernity initially thought its relation to nature as completely new, because it separated the 'subject' from the 'object' - a typically modern characteristic, to which Latour gave attention. While the second movement saw this supposedly new relation to nature in terms of domination, as we will detail further. Here is the central problem of the technological 'Enframing' and from which global warming became representative, if not a materialization, of modernity's partly deficient precepts.

The binary separation between 'object' and 'subject' is a highly debated problem that can only be underlined here as a characteristic of Western modernity at large, and that is best epitomized by the eighteenth century/early-modern philosopher Immanuel Kant's 'Copernican turn'. In the Critique of Pure Reason, Kant attempted to unravel the epistemological dispute on the origin of knowledge as being either empirical or cognitive, by asserting that, even if most knowledge unquestionably has empirical roots, the mind remains the focal point and the condition sine qua non for knowledge to even exist - and thus becomes the necessary condition for metaphysics itself to exist. This is what Kant calls the 'Copernican turn'. For Latour, this separation - of which the 'Copernican turn' is not the starting point but the most representative moment - is what allowed Westerners to think of themselves as inherently different from 'the others', the pre-moderns, as they thought this divide absolutely new.

It is within this new separation that the second movement, the one best representing the modern relation to nature, came into action more evidently: this relation to nature was thought in terms of domination, and this is what is of prime importance in our context. As the German philosophers Theodor Adorno and Max Horkheimer emphasized in Dialectic of Enlightenment, the ideals of the Enlightenment in Europe hoped to free human beings from fear of the unknown thanks to science, and allow them to control nature and its resources yet, not in a new way, but within a religious inheritance from which human supremacy was never questioned. As the authors pointed out, the Jewish and Olympian religion (to which we can add the Christian religion), called for domination. The two authors directly quoted the book of Genesis, a referential text in the Jewish and Christian religion as stating: “(...) 
and let them have dominion over fish of the sea, and over the fowl of the air, and over the cattle, and over all the earth, and over every creeping thing that creepeth up the earth."[19] For the authors, not only had the relation to nature barely changed, since the animals that were sacrificed in the past in place of God are still suffering the "tournament of the laboratory," with a couple of slight differences that the authors specified [20], but this also paved the way for dictatorship in Europe: the emergence of the subject and individuality better permitted, according to the author, the moulding and conformism into the mass. For the authors, this inheritance favoured the attempt at domination of man over nature, as much as of man over man. This is what is crucial to apprehend even in today's world and also what supplements Heidegger's argument.

Not only this, but the philosophical duo, Adorno and Horkheimer, even furthered their argument as far as to univocally qualify this dominative relation to nature and to humans as being "patriarchal."[21] Adorno and Horkheimer's critic relates to, and even goes beyond, the ways in which Robert Hunter described in Thermageddon the passion of his childhood for cars and motorcycles, when he recalled pinning posters of cars on bedroom walls and admiring the tailfins of Cadillacs, claiming that "this was manhood."[22] It is not exactly this masculine world that is at stake here, but something more deeply rooted than a mere addiction and dependence for car bodywork and rides. The problem is not one of gender, but of domination. For Adorno and Horkheimer, this 'patriarchal' relation to nature is in operation within these particular instances: when the mind serves for ruling and knowledge is used as a power. For them, this failure is the failure of the Enlightenment, when the ideals such as those of the early-modern philosopher and scientist Francis Bacon, who envisioned "the happy match between the mind of man and the nature of things," ultimately failed since, as the two authors forcefully stated: "What human beings seek to learn from nature is how to use it to dominate it and human beings" (the italics are mine).[23] Which in turn explains the authors' emphasis on the most paradoxical condition of the European Enlightenment: that it aimed at human's betterment, but saw the most radical and devastating dictatorships. Some of the Western precepts of modernity therefore urgently need re-assessment as Latour already pointed out.

In terms of war, even today, we have to admit that a couple of Western countries are still entangled in devastating wars, which have been displaced mainly to the Middle East. Hunter also underlined this aspect, when he stated that, beyond ecocides, there is an immediacy to look at this oil addiction politically. As he stated: "In purely political terms, oil has unleashed massacres, fortified criminal rulers, spawned atrocities, and served terrorism just about everywhere you look." [24] To which it can be added that energy firms, that are other than oil-orientated, are no less stained or necessarily greener. For example, the French nuclear corporation AREVA has long been criticized for the little regard it gives to radioactive contamination of the mines, landscape and area it exploits, particularly in the former French colony of Niger, as much as (and most importantly), for the actual workers on site.[25] Whereas paradoxically, the nuclear corporation AREVA intends to make a business out of the current crisis caused by global warming by advertising its services as 'C02-free', while still using fossil fuel powered boats to transport the processed uranium 
from the mines to the French continent. This shows again the exploitation of nature and humans by humans in such a concentrated form, and most importantly in a neo-colonial form, and it underscores again the repetitive problem of dominion (beyond the wars started for oil) which undoubtedly presses for a re-assessment of Western modernity. In the face of such a lack of ethics, in the case of AREVA's use of techno-scientific applications or corporate use at large, and as we already stated throughout this chapter, it becomes obvious that the cause of the current crisis is not merely technological, it is also human and cultural, and this aspect needs to be considered in the finding of a solution.

It must be said, however, that initially, the Western ideals of modernity had a reasonable justification - reasonable in the sense that it aimed at involving reason and rationality in decision making. At the origin of this modern relation to nature, the separation between 'object' and 'subject' lies, paradoxically, the particularly modern ambition for secularity. Indeed, one of the precepts of the Enlightenment, as it developed in Europe, was to prevent beliefs and superstition interfering in a given society's doings. Natural phenomena were thought to be interpreted differently, that is, empirically and assumed to be observed 'objectively' and, therefore, no longer as signs from God - which ultimately is of upmost importance. For Latour, the appearance of the scientific apparatuses, in the desire to observe natural phenomenon objectively, are in fact preceding Kant's 'Copernican turn' in the separation between the 'object' and the 'subject'. Nature and culture, object and subject therefore become separated and human beings considered as separated from nature another typical Western turn. Nature is endowed with a history and properties of its own and this, in order to prevent the use of natural phenomenon for political, ideological and religious agendas. However, as the two philosophers Adorno and Horkheimer argued and as we have already underscored, the mythological, magical and religious original interpretation of the world persists, even in our modern times, precisely through this dominative behaviour. Here is another seminal clue to some of the imminent issues we still have to face today.

Similarly to Adorno and Horkheimer, Latour also stated that this endless quest for domination found its limit. As he stated: "The repressed returns, and with a vengeance: the multitudes that were supposed to be saved from death fall back into poverty by the hundreds of millions; nature, over which we were supposed to gain absolute mastery, dominates us in an equally global fashion, and threatens us all. It is a strange dialectic that turns the slave into man's owner and master, and that suddenly informs us that we have invented ecocides as well as large-scale famine."[26] For Latour, capitalism is also to blame, and communism did not achieve better since, by wanting to prevent the exploitation of men by men, it emphasized it instead. The nuclear corporation AREVA is here again an example of what Latour underscored, as it certainly is the capitalist rules that pushed and still pushes forward this firm to try to sustain, at all costs, its position of leader in the restricted market of nuclear reactors. Competition is not, however, the main problem. In this example, the questions that in fact remain to be posed are the following: can sensitive technology, such as nuclear technology, be used and treated in the same way as any other marketable product? In addition, can competition afford to disregard ethical consideration of nature and humans? 
Not only this, but since we underscored the separation between 'object' and 'subject', we must acknowledge this modern attempt at secularity as failed once again- for even in the twenty-first century, one still thinks in terms of 'belief': on the one hand, the separation between the so-called 'climate-sceptics' and 'alarmists' forces one to claim if they 'believe' in climate change or not; while on the other hand, religious groups for instance, still question scientific empirical evidences such as Darwin's theory of evolution for instance. To come back to the climate-sceptics, this phenomenon must be analysed more carefully here, not simply for the rhetorical condition that we previously examined, the one labelling and differentiating the two categories, but also and primarily for what can be called a 'reversed religious justification'. It was precisely to prevent the justification of an act, a murder or a war in the name of God that the Western early-moderns moved toward secularity, in a joint effort that encompassed many social activities such as science, philosophy and art.[27] Yet this religious justification is reversed when the climate-sceptics use precisely the fact itself of being 'sceptics' and of not 'believing' in climate change as a justification for their economic interests (some scientists being referenced as having worked for Exxon) - interests that in some cases led to still current wars in the Middle East. The previous use of religious justification to cover economical and ideological stakes, is here re-enacted through corporate interests. Modernity's ideals of secularity clearly failed in this instance.

The present crisis, of which global warming is representative, is therefore wider than what we have tackled so far. It encompasses several cultural, political and economic stakes, about which we can do nothing but to underline them in this context. A re-assessment of the Western project of modernity is therefore crucial. However, and as the international community has been moving towards a global solution to refrain the change in climate, we need to pay heed to this particular global instance. One of the reasons for this urgency to analyse this need for a universal solution is that other ideals of the Western modernity need to be revised and it is important to consider them in our context.

\section{Universality I: Global warming in art and science}

Another of the characteristics of global warming is indeed that a universal solution is required, or rather, that a universal effort to reverse the current situation is demanded. In the humanities, universalism has long been critiqued, for it negates diversity and individuality. Yet in our context, the one of global warming, this demand upon us to find a universal solution is flagrant and absolutely necessary on many levels, levels that are important to highlight since they add to the list of characteristics of the Western development of modernity that need to be rethought.

In the first instance, this universal effort requires scientists from a large number of disciplines to collect data and to find a solution. The scope of this need for interdisciplinary cooperation is extremely wide and exceeds the field of climatology and environmental sciences. For example, the fields of paleo-climatology, volcanology, marine biology, meteorology, space and computer science play an important role in monitoring as well as working towards finding a solution. This need for interdisciplinary cooperation is such that the prefix 'climate' is sometimes added to some already pre-existing scientific disciplines. 
After dedicating much writing to demonstrate the extent to which the situation of climate change is nothing new, we must accentuate here that the scope of this interdisciplinary need is what is perhaps the most specific characteristic of the present situation, because the postmodern interdisciplinary cooperation is extensively required, more than it ever has been since the advent of modernity and even post-modernity.

The urgency of our current state is such that a new scientific field was created, with its 'climate experts', and this with no direct or major technological apparatus to define it. The international cooperation of scientists in this matter dates from the nineteenth century, but never did it encompass such a wide range of disciplines, that have only recently been grouped under the name 'climate science'.[28] As we already emphasized, techno-scientific disciplines succeeded one another, creating new fields according to new resources or apparatuses, as biotechnology would, for example, be characterized and defined by biotechnological apparatuses and a focus on genetic material. In the modern era, we have seen a succession of nuclear technology, space technology, biotechnology and even nanotechnology. Yet climate change has created a field of experts that cuts across the wide range of pre-existing disciplines. This is perhaps the most important and specific characteristic of climate change. The reason for this is simple: the effect of greenhouse gases affects the totality of the planet and of our ecosystem, whereas the scientific research, as it has been conducted in the modern West so far, has been based predominantly on the specialisation and autonomy of the fields. Specialization and autonomy are another of the precepts of modernity that we have previously emphasized, such as secularity and the separation between 'object' and 'subject' or 'nature' and 'culture'.

The specialization of the fields is a problem that Heidegger already spotted in is magnum opus Being and Time - so prominent in the humanities - even though the main argument of his piece is not directly directed at solving techno-scientific problems. Yet for him, the ontical sciences, or the empirical ones, make the mistake of trying to understand natural phenomenon from the restrictiveness of the delimitation of their own discipline. While at the same time, he also clearly stated the absolute necessity of the specialization of the fields in another essay titled Science and Reflexion, when he stated that "specialization is also not merely an unavoidable evil. It is a necessary consequence, and indeed the positive consequence, of the coming to presence of modern science."[29] The current paradox is now clearly evident and calls for interdisciplinary cooperation as perhaps never before, while requiring at the same time an advanced specialization of the scientists in the direct tradition of modernity's autonomy of the fields - which can sometimes become an obstacle as each discipline has its own specific language.

Yet we must acknowledge that this tension is however not always an obstacle and can become a force. The necessity of interdisciplinary cooperation has become so important that even the arts are being included into the effort and here in another from than a mere cultural barometer of interest or anxiety towards science that we previously analysed with Goethe's Faust for instance. For the last couple of decades, the two disciplines, art and science, have been deploring the ways in which they are separated and so distant from one another another result of the modern predicates of autonomy of the fields. Yet in this instance, one 
has to admit that the challenge that climate change represents today favours, if not forces, a proximity and cooperation. One of the reasons for this is that artists are no less Earth's citizens than are scientists, activist and politicians, and their statements and actions are therefore as important to cover as those from scientists, philosophers and experts.

At first glance one might think these artistic activities done in response to climate change are of peripheral importance. Some art protagonists themselves look at this type of art with a doubtfuleye, but disregarding the importance of artistic strategies would be a mistake. The efficiency is more subtle than one may think, for they work at a social level. A perfect example of this, among the myriad of artworks produced in relation to climate change that are equally as inventive as one another, is the work of the collective HeHe (Helen Evans and Heiko Hansen). In 2008, they organized a city-wide event in Helsinki, Finland, during which a green laser was flashed, over night, onto the cloud produced by the chimney of the Salmisaari power plant - a coal power plant. The laser was interactive in the sense that it would, in real-time, reduce or expand according to the consumption in electricity of the city. The piece was titled Nuage Vert (Green Cloud, Fig. 2) - the collective having an interest for human-made clouds at large such as cigarette smoke. [30] In order to realize the project, a joint effort between the artists and some experts was necessary, which is paradigmatic again of the current need for an interdisciplinary approach that post-modernity had already called for. The artistic event was made possible thanks to the teamwork of experts in various areas such as air quality monitoring, electrical engineering, laser technology and computer science.

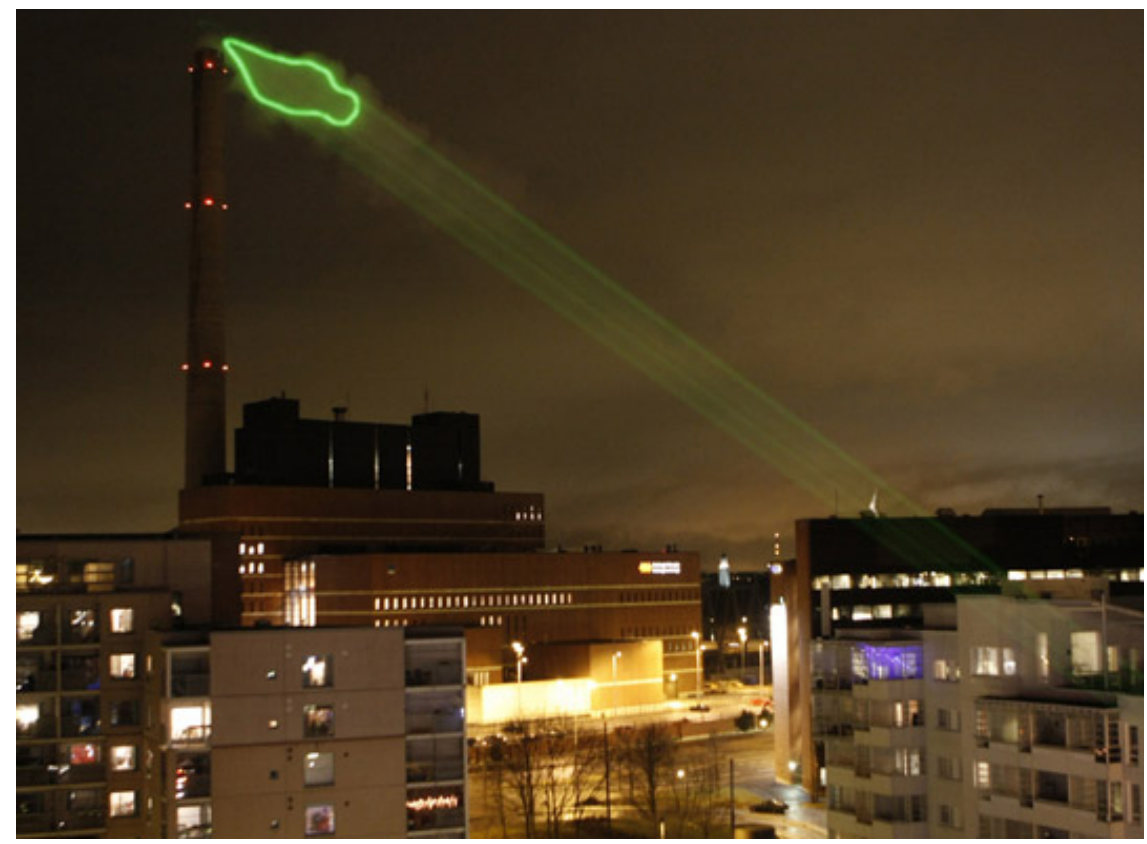

Figure 2. HeHe, Nuage Vert (Green Cloud), Helsinki, Finland, 2008. 
The specificity of the project is however manifold: on the one hand, not only did the artists give visibility to at least one type of greenhouse gas - a phenomenon that still remains an abstract idea for many since most power plants are usually remotely located and that the greenhouse gases are mainly invisible; while on the other hand, they also worked within the city itself, with an intensive mediation of the project on a local level. The artists asked the inhabitants to reduce their use of electrical appliances in order to change the length of the green cloud during the week of the event. HeHe not only displayed posters throughout the city, but they also toured primary schools to explain the project to children, knowing that they would, in return, ask their parents to participate in the project and, by way of consequences, that they would 'educate' their parents on their level of consumption - education being perhaps one of the most forceful technologies used by the collective in this project.

Another specificity of the project of importance here is the link that was finally reestablished between humans and their local and direct environment. We have already showed the modern dissociation between 'object' and 'subject', the separation between 'nature' and 'culture', and most importantly, the dissociation of the relationship cause-effect. Yet with Nuage Vert, more than a direct relation to 'nature', a cause-effect relationship is reestablished through the inhabitants' direct link with the remote production of greenhouse gases that were made visible - a link that has been ruptured generations ago and definitely needs to be re-established. The tension between the specialisation of the fields and the crossdisciplinary discussion is here clearly a strength..

It is on a similar plane of action that the fascinating artistic approach of the American artist and biologist Brandon Ballengée is also located. For decades Ballengée has been locally collecting deformed frogs, reptiles and amphibians in different parts of the world in order to determine the cause of their deformities. This is the 'Malamp Project' that he initiated in the late 1990s, among other equally important projects of the artist. [31] As with the collective $\mathrm{HeHe}$, interdisciplinary work is of central importance. Ballengée collaborated with numerous other scientists, such as Professor Stan Session, an amphibian specialist at Hartwick College, in New York, yet he also opens up his field trips to the public, in what he calls his 'eco-actions'. Here the link human beings and nature is re-built in a different fashion than the modern one, through the awareness of one's own local ecosystem (and therefore consistent with the modern ideals of enlightenment through knowledge). Ballengée's artworks take different forms, between the 'eco-actions' (Fig. 3) and the exhibition of physical artworks: the artist developed a process to preserve the specimens, that colours their bones and cartilages, therefore highlighting the deformities (Fig. 4). In the gallery space, large prints of the scanned specimens, as well as the preserved specimens themselves, are exhibited, therefore constituting unavoidable empirical evidence of these birth defects.

These birth defects have many causes, from parasites to predators and, unmistakably, from chemical pollution - a fact that has recently been under the spotlight of the media given the suddenly high numbers of eyeless prawns, fish with lesions and crabs without claws that have been fished up from the Gulf of Mexico and for which the 2010 BP oil spillage is believed to be the cause on the 2010 BP oil spillage.[32] Ballengée's strategy is therefore 
located at the tension between the modern ideals and mistakes, as much as at the tension between the global and the local and a re-connected cause-effect relationship.

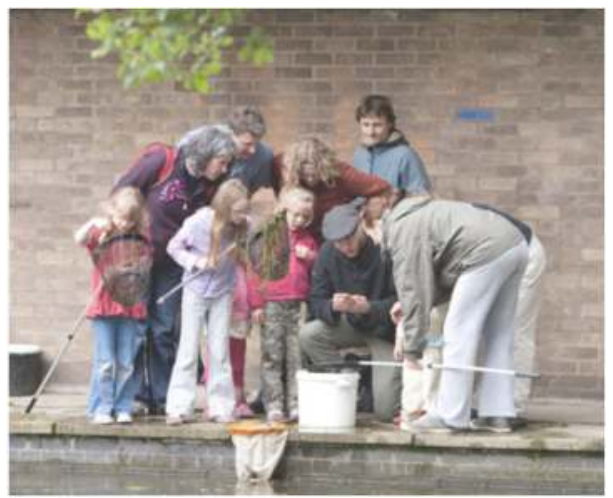

Figure 3. Amphibian Eco-Action, Yorkshire Sculpture Park, Wakefield, England, Photograph 2008 by Jonty Wild.

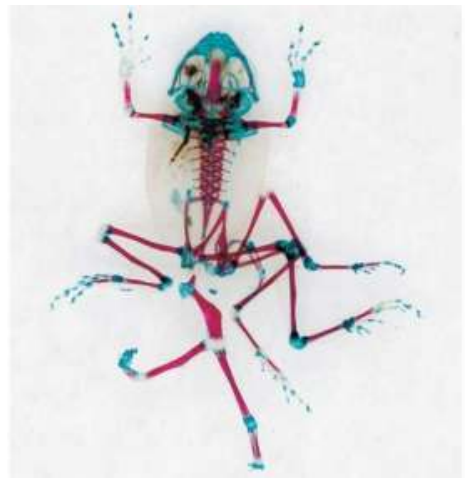

Figure 4. Brandon Ballengée, DFA 23, Khàrôn, Unique scanner photographic print of cleared and stained multi-limbed Pacific Treefrog, 2001/2007.

It must be said that this type of art is not the privileged strategy of individual artists on their own and sometimes encompass the cooperation of curators, museums and governmental or even independent founding bodies. The exhibition Lovely Weather for example was an artists-in-residency project in Donegal, Ireland, that was co-curated by Annick Bureaud and John Cunningham, with the help of Letterkenny Regional Cultural Centre, the Public Art Project of the Donegal County Council and the art/science journal Leonaro/Olats. [33] The primary aim of the exhibition however, and the specificity of its strategy, was to have a local approach to the problem of global warming. One of the artists in residence for instance, the Canadian artist Seema Goel, initiated a spinning and knitting workshop whose final items, some socks and hats, used patterns from translated data coming from the Irish Malin Head meteorology station and other meteorological data (Fig. 5). Yet the workshop has more ambition than simply materializing opaque data for individuals. This project was initiated 
after the artist came across a labelled 'Donegal sweater' that therefore appeared to be produced locally, but was in fact made in Thailand for the clothing corporation American Eagle. The intention of the project was primarily to use sheep's wool collected from local farms (which has almost no value for the farmers) and to spin and knit with it, therefore producing some typically and finally authentic Inishowen/Donegal wool. With this artwork, the problems of the exploitation of humans by humans, of the disappearance of local industries in the age of globalization and of the use of fossil fuel means of transportation in the exportation of products such as those produced by American Eagle, is here solved in one spin of a bobbin: the workshop started a wool cooperative which is still active today.

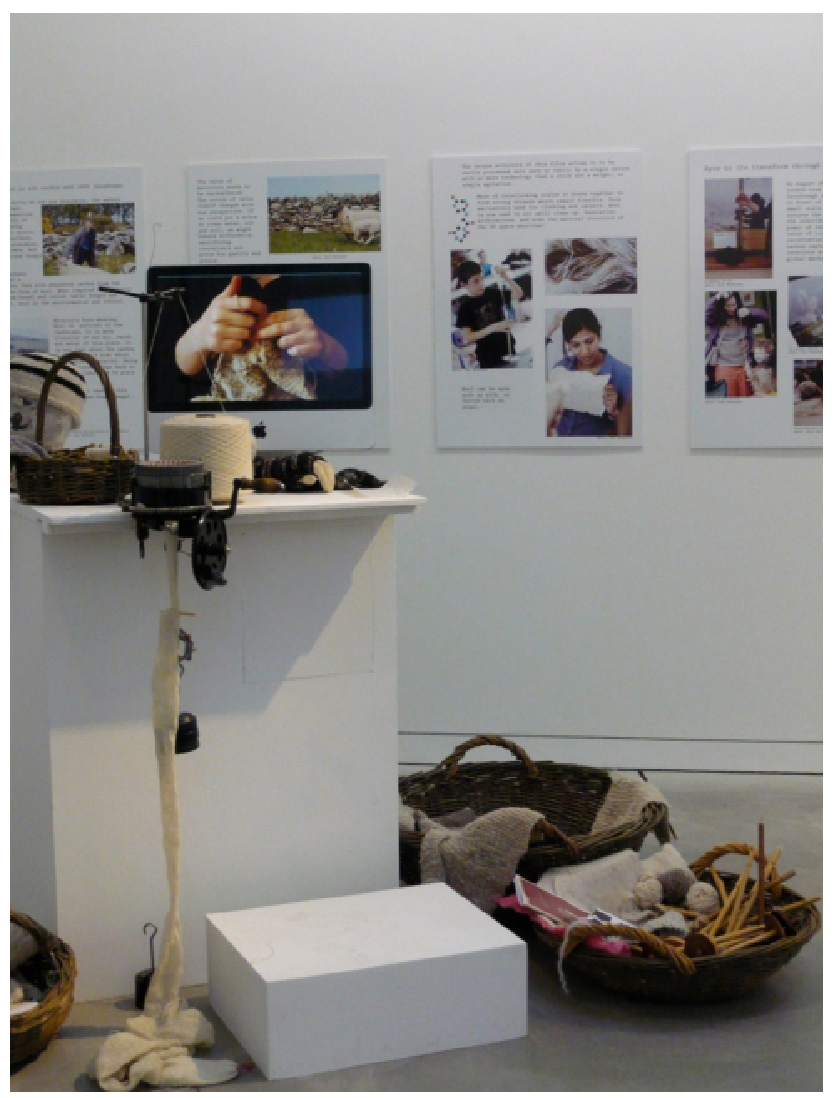

Figure 5. Seema Goel, "Carbon Footprint", Lovely Weather project, exhibition view, photo Annick Bureaud.

To come back to the need for interdisciplinary work, it must be said that if this post-modern need for teamwork is of crucial importance and a characteristic of the consequences of climate change, this interdisciplinary effort cannot, once again, be considered entirely new. In the past, and in the pre-modern West, art and science 
were linked by the fact that they were directed towards cult and the scriptures. Religion was the unifying force. In Western art (or 'craft' since art was considered as such at that time), Renaissance painters or even the Greek sculptors and architects devoted their work for communication with the Gods and for the illustration of religious or divine characters. The form and the content of the work of art was principally directed toward a cult and was an object of cult, as with the famous Renaissance frescoes and Greek temples. The same applied in 'science' - or in science as 'knowledge' -since science as a professional discipline only emerged in the late 1830s. During the Middle Ages for example, Paul of Burgos, a prominent Spanish religious character and exegete stated and published that the Earth had two centres of gravity, one for the soil and one for water.This was done in order to conform to the narrative of the creation of the universe by God, as described in the book of Genesis, when God immersed the Earth with water and ordered on the third day for dry land to appear.[34] The development of new techniques, craft, and the knowledge of the cosmos and political decision where unified through religious beliefs.

Trans-disciplinary cooperation is therefore not new and it is not the first time to be put to work since the advent of the modern autonomy and specialization of the fields. Other examples, and closer to us, are the totalitarian regimes, such as Nazism in Germany and Communism in Russia, that saw the enforcement of cooperation between art and science, as with other social activities, in the service of the regime. Yet their aims were ideological and their scope national. The rarity of the current situation is such that there is no political-ideological input, nor particular national stakes - or at least not at first glance. The scope is transnational and trans-disciplinary (even though we have to note here that the bulk of what some call 'climate art' is mainly created by Western artists). However, climate change and the threat of it represents a call for a wider universal effort and, paradoxically, a demand for cooperation and simultaneously specialization, therefore putting modernity's autonomy of the fields into question. We previously showed how the origin of the current crisis is not technological and we have now to acknowledge that the finding of a solution does not necessarily include technological devices. Not only this, but in the ontological approach we have conducted so far, human beings were considered as a whole, as if there was only one human category, one unconsciously thinking of its relation to nature in terms of domination. Yet are all humans the same? With the same background, history or culture? Do they all share the same role in the triggering the current crisis? Acknowledging this will help us to give perspective to the call for a universal solution for global warming and underline better the role played by the Western project of modernity in the present situation.

\section{Universalism II: International politics, from the competition of the empires to the Cancun agreement}

At another glance and after underlining the paradox between universalism (or the need for interdisciplinary work) and the specialization of the fields, climate change implies not only a 
joint scientific effort, but also a joint effort on behalf of all Earth's citizens, no matter their origins, nationality or activities. This is what is utterly new in this situation, climate change is a global phenomenon that concerns each of us. Yet what we must clearly ask is the following question: is ultimate universalism even achievable?

Once again, we can put forward the claim that ideally 'we', the citizens of the Earth, 'we' the scientists, the corporate energy agencies, the politicians of the world, the non-experts in a word 'we' the human beings at large, can, should and will combine our forces and will work together. After all, that is precisely what Albert Einstein hoped for when he called for unity in his Manifesto against weapons of mass destruction, written with Bertrand Russell in 1955. As they stated: "We appeal as human beings, to human beings: Remember your humanity, forget the rest."[35] For Einstein and Russell, no matter what the issue is, "whether Communist or anti-Communist, whether Asian or European or American, whether White or Black, then these issues must not be decided by war."[36] We must be optimists and imagine that this plea will be met today, given the necessity of a transnational unification to solve the problem. Yet we must admit that, in the case of nuclear weapons, this universal solution was certainly not reached, even today. The recent wrestles between Western countries and Iran on Iran's nuclear programme or the possible use of depleted uranium in the 1991 Iraqi war are evidence enough. In the case of nuclear weapons, a universal agreement still appears hardly achievable. Consequently, can a universal agreement be achieved in order to battle against the changes of climate of the Earth, given the imminence of the threat?

The divides that prevent a unique solution are in fact numerous and can only be mapped out here in a restricted form, before looking at a couple of solutions. One of the main causes of dissension is of course economic, caused by the many competing national interests. The American refusal to sign the Kyoto protocol, followed by the Russian hesitation, is paradigmatic of this difficulty in reaching a universal agreement (and therefore a solution) because of national interest. The George W. Bush administration declared following the protocol that it would gravely endanger the US economy, while Russia had a similar claim before finding more support from the European Union.

A second important cause, preventing universal agreement, which we have already underscored, is the divide between the climate-sceptics and the others. The interests of the large industrial and energetic corporations - or the 'Carbon Club' as Hunter calls them are still too important for them to feel concerned by ethics in any form. Preventing ecocides does not guarantee economic benefits - of this we already know the problem. Yet this divide does not concern the Carbon Club alone, nor even the divide among the scientists at large, but is spread among the world population to the point that a very controversial publicity film was launched - then withdrawn - as part of a British and global campaign called 10:10. The campaign aimed at reducing carbon emission by ten percent in 2010, following the Copenhagen accords, and in order to give a sense of responsibility to individuals, companies and businesses globally.[37] Yet the four minute 
film, titled No Pressure and directed by Richard Curtis depicts a series of graphic explosions of persons, including children, in their daily life, in a work environment, at school or on a football pitch. The individuals are being killed on screen because they showed signs of scepticism or are lacking enthusiasm with regard to the 10:10 campaign.[38] Although withdrawn from the campaign even before broadcast, the video spread on the Internet and caused a public outcry. This particular instance is of importance, first because climate change is still contested even today and tends to fade away in public debates. As the organization stated, to explain their video: "With climate change becoming increasingly threatening, and decreasingly talked about in the media, we wanted to find a way to bring this critical issue back into the headlines whilst making people laugh."[39] Secondly, this aspect is of importance because it shows that it still takes a lot of marketing strategies, provocation, financing and imagination to sustain concern from the public with regard to the problem. As Franny Armstrong, the founder of the 10:10 campaign stated: "We've 'killed' five people to make No Pressure - a mere blip compared to the 300,000 real people who now die each year from climate change."[40] Sensitizing individuals appears to be as difficult as forcing energy corporations comply. Most of all, we have to realize that it takes time, since the first conferences on climate change in the 1980s, for the idea of the absolute necessity of cultural change to make its way into people's mind and for this idea to remain.

Another peripheral yet still significant cause preventing general agreement that was quite apparent during the moments of the Kyoto protocol, and beautifully pictured by Hunter in Thermageddon, is based on political regimes and cultural differences. The most obvious example is again the George W. Bush administration's justification for its reluctance in taking part to the global effort, that this reluctance had to do with the fact that it would affect the 'American life style itself' and its car-addiction habit. Another cultural tension also described by Hunter was the dismay generated by a discussion between the members of an Arab and a Canadian delegation. According to Hunter, in order to reply to the statement of the Arab representatives, who argued for the importance of keeping low prices for petrol, so "the poor can drive to work," [41] the Canadian delegate suggested a redistribution of wealth instead. Not only was the difference between the two understandings of the problem blatant, but the Canadian delegate was a female and this caused her to be swiftly dismissed, as Hunter recalled, and to which he added "but what could they do in a foreign democracy where women have the vote?"[42] How can one find a general consensus in spite of the cultural, ideological, economic and political differences, which should be a force enriching the debate but which in this condition rather appears as an obstacle? Here again, as we already pointed out the finding of a solution does not involve purely technological concerns.

Adding to this aspect is the divide between the East and the West, or between the developed and industrialized countries. Apprehending this divide is of prime importance, for it relates to the urgency of revising the Western project of modernity itself and also 
adds to the cultural histories that consciously or unconsciously precondition our relation to nature and human beings. This problem was again portrayed by Hunter, for instance in the lecturing of an American representative to delegates of developing countries such as China, Brazil and India, on the effort the latter countries would have to produce to reduce carbon emission - to which somebody in the audience finally said in order to point out the paradox: "A nation of sports utility vehicles lecturing nations of bicycles?"[43] This paradox is representative of a wider problem whose causes are, again, deeply rooted, politically and historically. The divide between the East and the West is a consequence of the Western project of modernity as this project was linked to the building of the European Empires.

On the one hand, it would be absolutely unethical to avoid mentioning here that the emission of greenhouse gases is an unpredicted yet direct outcome of the modernization of the West through the two Industrial Revolutions, which was initiated in Europe and in the West at large. It is this problem that now affects the totality of the planet and countries hence Bruno Latour's instance on the importance to revise Western modernity. In We Never Have Been Modern, Latour also alerted us to the importance of considering this divide. He asserted that modernization was brutal toward the pre-moderns and that postmodernization now represents another challenge. As he stated: “Imperialist violence at least offered a future, but sudden weakness on the part of the conquerors is far worse for, always cut off from the past, it now also breaks with the future. Having been slapped in the face with modern reality, poor populations now have to submit to post-modern hyperreality."[44] Because the Western techno-sciences are being exported, a revision of their use and applications is doubtlessly necessary.

However, on the other hand, we must also consider the fact that the idea of modernity itself was precisely constructed through this divide between the East and the West. The great Universal Exhibitions that were staged in the late nineteenth century constitute the best example. In these exhibitions, Western scientific devices and art objects were opposed to colonized cultures presented as backward and archaic. The 1889 exhibition, that was held in Paris, even gathered from the colonies some inhabitants and their habitats, that were exhibited in human zoos and contrasted to reconstituted medieval houses (Fig. 6). The narrative suggested via these juxtapositions was the superiority of the Empire, illustrated by the demonstration of technological superiority. Here is a particularly flagrant example of the patriarchal use or understanding of technology and humans as critiqued by Adrono and Horkheimer. The narrative in turn was used especially by the French Empire to justify its imperialist wars that were nonetheless initiated in the midst of a competition of strength and power between the few Empires of Europe.

This implemented fracture, between the East and the West, is also accentuated by the fact that the industrialization of the developing countries is now asked to be curbed because of the problem of gas emission - a crisis which originated in Western and illustrates again the importance to consider parameters that are no technological in the finding of a resolution. 
Moreover, in this necessary attempt at finding a common consensus, how can international organizations, such as the United Nations and UNESCO succeed? By trying to universalize a method of calculation of anthropogenic emissions, by quantifying limitations or reduction commitment according to countries as the Kyoto Protocol tried to do, in such an attempt at finding a common equation to filter all discrepancies and level them down to equality in the task of reducing greenhouse gas emission, how can one rationalize and put into numbers the richness and variety of paths that each country follows (whose borders are not always stable) as much as the differences in power that still divide the world?
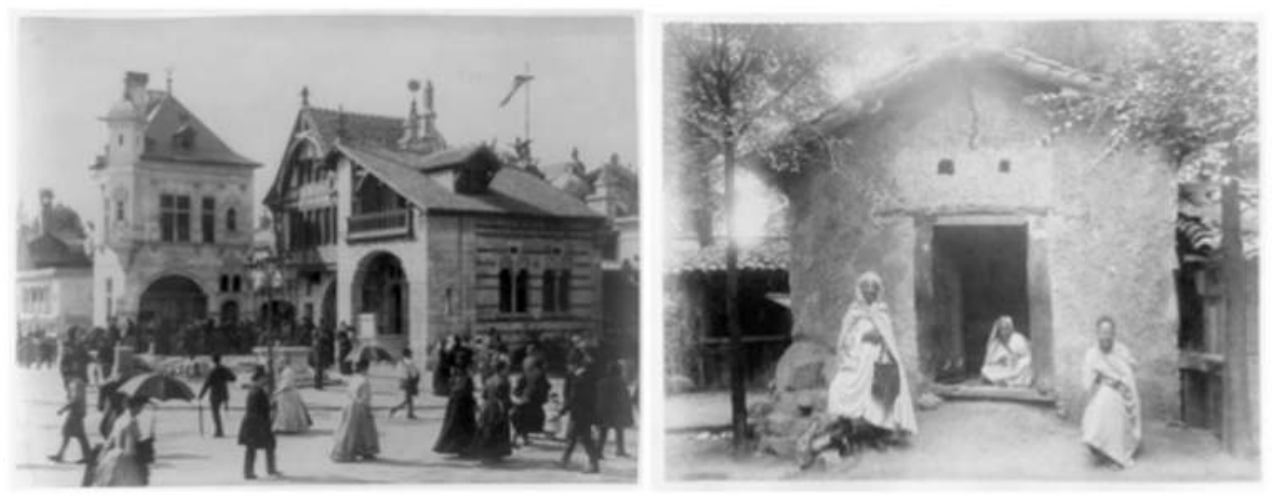

Figure 6. Medieval and Renaissance Houses (left), and Algerian/Kabyle House and Family (right), Paris, Universal Exhibition of 1889, Library of Congress, Washington. See also Alfred M. Picard, Exposition universelle internationale de 1889 à Paris: Rapport general, ed. 10 vols. Imprimerie nationale, Paris, 1891-1892.

Universalism and diversity are here again clearly at stake and a recurrent tension. The problem of climate change is therefore taken here into another context, beyond the techno-scientific or even philosophical problem. The greatest challenge for today's world is therefore located in this particular divide, when the intricate geopolitical interests that were at play in the advent of modernity in the West are still at stake today. The example of the exploitation in a uranium mine by the French company AREVA already described, the lack of ethics in the exploitation of mines and workers of the former colony of Niger, clearly shows the extent to which a more profound change in human activities at large is needed.

In the midst of these difficulties, we must however consider the late appearance on the horizon of international and socio-political breakthroughs. The Barack Obama administration, for instance, re-oriented the US policy towards more contribution with the 
Copenhagen Accord of 2009, then with the Cancun Agreement (reached at a United Nations conference on climate change in Mexico in 2010). An international fund, called Green Climate Fund, has even been established. This fund would help developing countries financially for climate-oriented programmes, projects and policies, which constitutes a fantastic step forward even though its financing is not yet defined. However, no matter how great these political decisions are, they are also dependent on the integrity, good will and the seriousness of the political leaders as individuals, and are therefore bound to them - showing here again that the solution to the problem is not merely technological.

\section{Conclusion}

As we just argued, even if we develop a revolutionary technological device, the current crisis might well be fixed, but will this also prevent the misuse of technology? In other words: will the technological apocalypse be permanently stopped or simply delayed? At present, they are some solutions in sight, along with international cooperation. Yet if the search for sustainable sources of energy is developing, how sustainable are the efforts on a socio-political and economic level given that the world is still affected by international conflicts and exploitation of humans by humans? Furthermore, within the continuous effort that is incontestably and unconditionally needed on the part of the scientific research, how will the numerous future technological innovations adequately serve humans with respect to the diversity of their place of birth, history and culture and this, beyond the Eastern/Western divide? In order to face the persistent misuse of scientific applications that started to be dramatically recurrent since the $19^{\text {th }}$ century, the parameters to consider in addition to the techno-scientific ones are therefore numerous. Without revising the interaction of humans towards their environment, without realising that humans are 'the one spoken too', as Heidegger stated, and not the ones controlling nature, can the centuries-long technological misuse (or 'Enframing' to use Heidegger's vocabulary) be stopped? Without a re-adjustment of the patriarchal understanding of the world - and most importantly: of humans - that Adorno and Horkheimer underlined, and the inheritance of the religious call for domination over nature, will we solve the problem? In the search for a solution, the separation between developed and industrialised countries, the impact of colonization and of post-modernity, the impact of the lobbyists and of the patriarchal/dominative behaviour in any place of the world must be addressed.

To be more precise, within these ideal yet necessary revisions, of the interaction of humans with their environment and with humans, it in fact is the modern split between nature and culture, as much as the modern secularity, that are at stake. As we already pointed out, it indeed is the western project of modernity at large that needs to be revised as Bruno Latour already argued in the 1990s. In We Never Have Been Modern, Latour urged for a revision of some of the predicates of modernity, in particular the 
separation between 'object' and 'subject'. Not only this, but for him, it is the modern idea of progress itself that needs to be reconsidered, since the modern mistakes, accidents and disasters should equally be considered instead of an idea of technological and social betterment, where the future is envisioned as necessarily better than the present. Is it not indeed this precise mythical understanding of modernity that has led an entire generation to leave a legacy of pollution of thousands-year radioactive waste in the hope that a solution will be found by the future generations, then imagined to be ultratechonologised? To paraphrase the notorious nineteenth century French poet Charles Baudelaire: if no one cannot dispute the fact that our lives are better today than they would have been a hundred years ago, how can one bet on their betterment in the future? A century later, the same question still imposes itself, which finally urges to ask: will we learn from our mistakes?

\section{Author details}

Gabrielle Decamous

Faculty of Language and Cultures, Kyushu University, Fukuoka, Japan

\section{References}

[1] Hunter R. Thermageddon, Countdown to 2030. New York: Arcade Publishing Inc; 2002.

[2] Derrida J. No Apocalypse, Not Now, (full speed ahead, seven missiles, seven missiles). Diacritics. Summer 1984; p. 23.

[3] See Gunter A. La Menace atomique. Considérations radicales sur l'âge atomique (The Atomic Threat. Radical Considerations). First published in 1960.

[4] Blanchot M. The Apocalypse is Disappointing. In Friendship. Op. Cit., p. 104

[5] Op., Cit., p. 107.

[6] See Jowit J. British campaigner urges UN to accept 'ecocide' as international crime. The Guardian Friday 9 April, 2010.

http://www.guardian.co.uk/environment/2010/apr/09/ecocide-crime-genocide-unenvironmental-damage (accessed 14 April 2012). For the ecocide campaign, see http://www.thisisecocide.com/.

[7] Idem.

[8] See Buchanan R. D. Playing with Fire. USA: Oxford University Press; 2010.

[9] Said E. Orientalism, London: Penguin; 1977; p.83.

[10] On the use of artists by corporations, along the activist/artistic responses to nuclear warfare see my article Nuclear Activites and Modern Catastrophes: Art Faces the Radioactive Waves. Leonardo Journal MIT Press 2011; 44 (2) 124-132.

[11] Heidegger M. The Question Concerning Technology. In The Question Concerning Technology and Other Essays. New York: Harper Torchbooks; p. 23. 
[12] Op. Cit, p.16.

[13] Op. Cit, p.17.

[14] Op. Cit, p. 15.

[15] Derrida. J. No Apocalypse, Not Now, (full speed ahead, seven missiles, seven missiles)'. Op. Cit., p. 23.

[16] Heidegger M. The Question Concerning Technology. Op. Cit., p. 25.

[17] Op. Cit., p. 27.

[18] Latour B. We Never Have Been Modern. Cambridge: Harvard University Press; 1993; p. 8-9.

[19] Genesis I. Quoted by Adorno, T. W. and Horkheimer M. In Dialectic of the Enlightenment, Philosophical Fragments. Stanford: Stanford University Press; 2002. First published in 1944; p. 5.

[20] According the author, there is a major difference, according to the author, between the ritual sacrifice and laboratory experiments, in the way that the experiment needs the specificity of the one being experimented, being an atom or a rabbit, while sacrifice was more flexible. Op. Cit., p. 7.

[21] Op. Cit., p. 2.

[22] Hunter R. Thermageddon: Countdown to 2030. Op. Cit., p. 26.

[23] Adorno T. W. and Horkheimer M. Dialectic of the Enlightenment. Op. Cit., p. 2.

[24] Hunter R. Thermageddon: Countdown to 2030. Op. Cit., 32.

[25] Greenpeace conducted a research onsite and concluded to unacceptable conditions for locals and workers, see

http://www.greenpeace.org/international/en/news/features/AREVAS-dirty-littlesecrets060510/ (accessed October 2011). From personal sources, I have been explained that, even if AREVA constructed a hospital for its workers, it only is open to current workers, not retired ones. The retirement age on site is however very young, which forbids any treatment of eventual cancer due to the radiations. At the time of my inquiries (summer 2009), I have been told that, as an example, a former mineworker had died of cancer at age 30, leaving a family behind.

[26] Latour B. We Never Have Been Modern. Op. Cit., p. 8-9.

[27] On the joint cultural effort between science, philosophy and art toward a secular society in Europe, as much as on the importance to underscored this failed attempt in a world where non-secular countries such as Iran are targeted, see my in my article: Bridging the Gap: Art, Science, Philosophy-Modernity in Question. The International Journal of the Humanities 2012; 9 (8) 185-194.

[28] On the history of climate change and of scientific professions relating to global warming, see Weart S. R. The Discovery of Global Warming, March 2011.

http://www.aip.org/history/climate/internat.htm (accessed March 2012).

[29] Heidegger M. Science and Reflection. Lecture given in August 1954 in preparation of The Question Concerning Technology for the series of conferences The Arts in the 
Technological Age. In The Question Concerning Technology and Other Essays. New York: Harper \& Row; 1977; p. 169.

[30] For more information on the project see http://www.pixelache.ac/nuage-blog/. The project won the Environmental Art Award, the Ars Electronica Golden Nica and the 01SJ Green Prix for Environmental Art in 2008. In 2010, the collective recreated the event in France, in Ivry-sur-Seine. A video of the event is available at

http://vimeo.com/17350218 (accessed April 22nd).

[31] For more information, see Brandon B. Malamp, The Occurrence of Deformities in Amphibians, Nicola T. and Miranda P. Editors. The Arts Catalyst and the Yorkshire Sculpture Park; 2010. See also:

http://greenmuseum.org/content/work_index/img_id-371__prev_size-0_artist_id-

19_work_id-86.html (accessed 22 April 2012) and the fantastic article by Sevier

L. Deformed toad artist hopes to win public sympathy for amphibians . Ecologist. 30 March 2010.

http://www.theecologist.org/how_to_make_a_difference/wildlife/451908/deformed_toa d_artist_hopes_to_win_public_sympathy_for_amphibians.html (accessed 22 April 2012).

[32] See Dahr J. Gulf seafood deformities alarm scientists. Al Jazeera 20 April 2012. http://www.aljazeera.com/indepth/features/2012/04/201241682318260912.html, （accessed 22 April 2012).

[33] For more information, see Bureaud A. Lovely Weather: Reflecting on the Letterkenny Donegal Art \& Climate Residencies and Exhibition'. Leonardo Journal MIT Press 2011; 45(2) 182-183.

[34] See Grant E. Star, and Orbs, The Medieval Cosmos, 1200-1687. Cambridge: Cambridge University Press; 1996.

[35] Russell B. and Einstein A. The Russel-Einstein Manifesto. London. 9 July 1955. http://www.pugwash.org/about/manifesto.htm (accessed December 2010).

[36] Idem.

[37] See http://www.1010global.org/.

[38] See Curtis R. No Pressure. 2010.

http://www.youtube.com/watch?v=sE3g0i2rz4w\&feature=player_embedded (accessed 23 April 2012). Surprisingly enough, Curtis is also credited for films such as Love Actually an Four Weddings and a Funeral.

[39] Organisers quoted by Singh A. In Richard Curtis and an explosion of publicity. The Telegraph. 2 October 2010.

http://www.telegraph.co.uk/news/celebritynews/8038113/Richard-Curtis-and-anexplosion-of-publicity.html (accessed 22 April 2012).

[40] Idem.

[41] Hunter R. Thermageddon: Countdown to 2030. Op. Cit., p. 114.

[42] Idem. 
[43] Op. Cit., p. 120.

[44] Latour B. We Never Have Been Moder. Op., Cit., p. 180. 